\title{
Prolapsed Giant Cervical Fibroid Polyp
}

\author{
${ }^{1}$ Mohita Agarwal, ${ }^{2}$ Saroj Singh, ${ }^{3}$ Rachana Agarwal, ${ }^{4}$ Shalini Jaiswal
}

\begin{abstract}
Giant cervical fibroid polyps causing diagnostic dilemma are rarely encountered in gynecologic practice. The objective of this case report is to document a case of huge cervical polyp large enough to cause prolapse of the otherwise normal uterus and cervix. A 35 years old multipara presented with heaviness in the vagina, pain in lower abdomen for 2 years and something coming out per vaginum, off and on vaginal bleeding and foul smelling discharge for 1 week. On local examination, grossly hypertrophied cervix was seen prolapsed outside the introitus and a large mass about $20 \times 18 \mathrm{~cm}$ apparently arising from the posterior lip of the cervix. On per rectal examination, uterus was atrophied. Pap smear and showed only inflammatory changes with no evidence of malignancy. After four blood transfusion and control of local infection with systemic antibiotic, patient was taken for surgery. Postoperative recovery was uneventful histopathological report confirmed fibroid-polyp. Although giant cervical fibroid is rare, it may masquerade as neglected 3rd degree uterovaginal prolapse or massive enterocele as in our case. Proper evaluation is needed to make an accurate diagnosis, anticipate operative challenges and strike a judicious and rational approach about deciding the route of hysterectomy.
\end{abstract}

Keywords: Enterocele, Giant cervical fibroid polyp, Uterovaginal prolapsed.

How to cite this article: Agarwal M, Singh S, Agarwal R, Jaiswal S. Prolapsed Giant Cervical Fibroid Polyp. J South Asian Feder Obst Gynae 2016;8(1):77-78.

Source of support: Nil

Conflict of interest: None

Date of received: 21 November 2015

Date of acceptance: 19 February 2016

Date of publication: March 2016

\section{INTRODUCTION}

Leiomyoma is the commonest of all uterine and pelvic tumors, with an incidence of almost $20 \%$ in women of reproductive age group. Cervical fibroids account for $2 \%$ of all fibroids. ${ }^{1}$ They arise from either supravaginal or vaginal portion of cervix. They are classified as anterior, posterior, lateral and central depending on their site

\footnotetext{
${ }^{1,3}$ Assistant Professor, ${ }^{2}$ Professor and Head

${ }^{4}$ Junior Resident (3rd Year)

${ }^{1-4}$ Department of Obstetrics and Gynecology, Sarojini Naidu Medical College, Agra, Uttar Pradesh, India
}

Corresponding Author: Mohita Agarwal, Assistant Professor Department of Obstetrics and Gynecology, 32/75-A/4, Pengoria Medical Centre, Rajpur Chungi, Agra-282001, Uttar Pradesh India, Phone: 9897221006, e-mail: bestmolly@gmail.com of origin. Each fibroid presents differently. Cervical leiomyoma is commonly single and is either interstitial or subserous. Rarely, does it become submucous or polypoidal? Giant cervical polyps are described as polyps greater than $4 \mathrm{~cm}$ in size and are rarely seen in clinical practice. Only handful of cases have been reported in the literature. 2,3

We are documenting a case of a huge and complex cervical fibroid polyp $(20 \times 22 \mathrm{~cm})$ as a cause of cervical prolapse.

\section{CASE REPORT}

Mrs X was a 35 years old hindu married para two female who presented in the labor room of the Department of Obstetrics and Gynecology, SN Medical College, Agra, on 2nd July 2015, with the complaint of something coming out per vaginum, off and on vaginal bleeding and foul smelling discharge for 1 week. She complained of heaviness in the vagina and pain in lower abdomen and back for past 2 years. There was no associated bladder or bowel dysfunction. She had two full term normal vaginal home deliveries. Her last child birth was 4 years back. Her last menstrual period was on 30 June 2015.

At the time of admission, she was in a low general condition, very pale looking, febrile (temp 100.2F) with an offensive odor about her. Her blood pressure was 90/60 mm Hg and pulse rate was 104/min. Her abdomen was soft and nontender. On local examination, grossly hypertrophied cervix was seen prolapsed outside the introitus and a large mass about $20 \times 18 \mathrm{~cm}$ apparently arising from the posterior lip of the cervix. The mass was about $20 \times 18 \mathrm{~cm}$ in size with areas of suppuration and bleeding (Fig. 1). Per speculum examination could not be

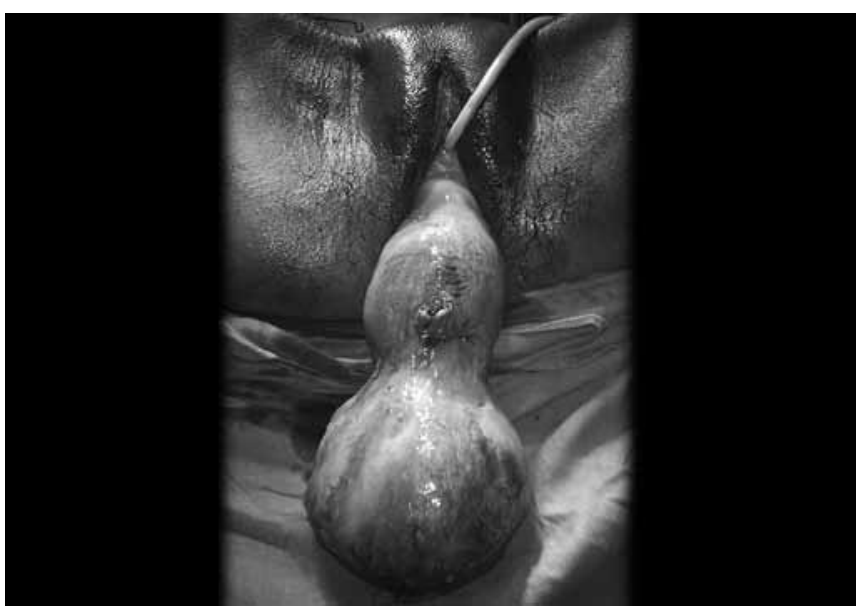

Fig. 1: Prolapsed fibroid polyp arising from posterior cervical lip 


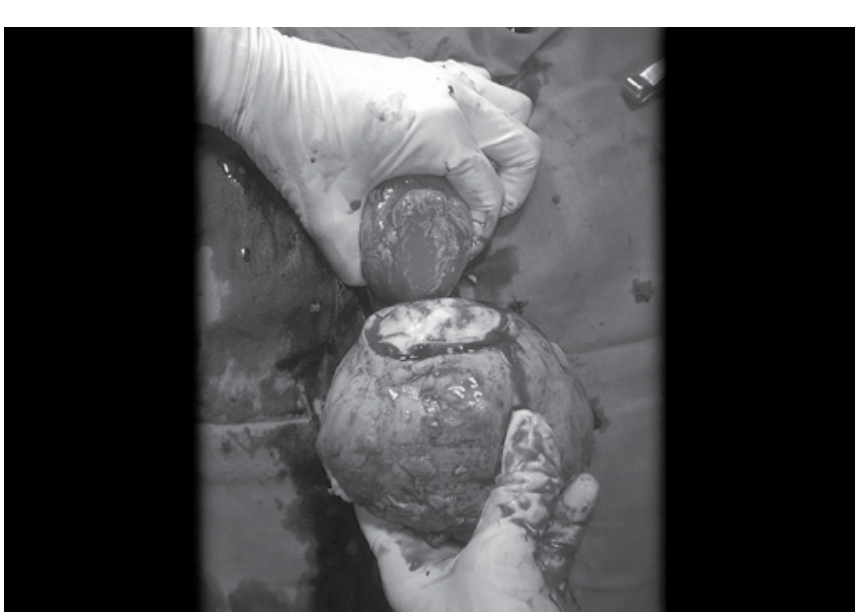

Fig. 2: Fibroid post excision

performed. On careful palpation, the mass was firm and nontender. On per vaginal examination, uterus was small in size and the fornices were clear. Per rectal examination confirmed the presence of normal parametrium and rectal mucosa and an atrophied uterus. Ultrasound findings reported uterine dimensions of $3 \times 3 \times 4 \mathrm{~cm}$. Pap smear showed only inflammatory changes with no evidence of malignancy. Her hemoglobin $(\mathrm{Hb})$ was $4 \mathrm{gm} \%$, total leukocyte count (TLC) was 17000/cumm and differential leukocyte count (DLC) was P76L20. Rest all investigations were within normal limits. The probable diagnosis of 3rd degree uterocervical descent with posterior cervical fibroid polyp was made.

She was admitted and placed on massive antibiotics (metronidazole, ceftriaxone and clavulanate potentiated amoxicillin), and frequent applications of antiseptics and sumac dressing to the mass. Four units of blood were transfused. The case was then taken for vaginal myomectomy followed by hysterectomy.

The first incision was given on the posterior aspect of the mass and thereafter the mass was excised completely (Fig. 2). The vaginal hysterectomy was then carried out successfully. Postoperative period was uneventful and the patient was discharged on the 7th postoperative day. Histopathology confirmed it to be a leiomyoma.

\section{DISCUSSION}

The present case of giant cervical fibroid was the first case in our center in the past 10 years thus, confirming its rarity. One such case of a huge cervical fibroid measuring $20 \times 10 \times 7 \mathrm{~cm}$ prolapsing outside the uterus has been reported by Surana et al (2014) from Ahmednagar. ${ }^{4}$ Another case of a prolapsed fibroid polyp measuring $18 \times 15 \times 12 \mathrm{~cm}$ has been reported from Nigeria. ${ }^{5}$ These cases were reported in perimenopausal women in their fourth or fifth decade of life unlike our 35 years old case.

The symptoms of mass prolapsing outside the vagina together with foul smelling vaginal discharge and bleeding in our case was consistent with that reported in literature.
Quite frankly, the presence of this huge fungating mass at the introitus in this patient was confusing but most reminiscent of a neglected 3rd degree uterovaginal prolapsed with cervical hypertrophy and decubitus ulceration. From previous reports, such huge introital lesions have been diagnosed as cervical malignancy, ${ }^{6}$ uterine rhabdomyosarcoma, ${ }^{7}$ etc.

The histology of our case reported a vascular leiomyoma with no evidence of malignant change.

Carcinomatous change occurs rarely in cervical polyps (seen only in $1.7 \%$ of cases). Several authors have contradicting views as to whether excisional biopsy is a more prudent approach or prior biopsy to confirm the diagnosis before resorting to surgery. In an environment like ours where cervical carcinoma is very common we may opt for biopsy first but this will only prolong morbidity and discomfort in the critically ill. Thus, it has been suggested that biopsy of these tumors before excision may not be necessary ${ }^{8}$ Careful evaluation, definition of anatomy and good clinical judgment should decide the course of management. If histology eventually shows malignant degeneration, appropriate therapy can always be advanced.

\section{CONCLUSION}

Giant cervical fibroids are rare and their diagnosis can be quite challenging. It may masquerade cervical malignancy or uterine inversion and prolapsed and proper evaluation is needed to make an accurate diagnosis. Hospitalization, clinical optimization, thorough evaluation and clear definition of pathology coupled with meticulous surgery under appropriate anesthesia, remain the mainstay of successful management of gravely ill patients presenting with a bizarre introital pathology as seen in this woman.

\section{REFERENCES}

1. Kaur AP, Saini AS, Kaur D, Madhulika, Dhillon SPS. Huge cervical fibroid-unusual presentation. J Obstet Gynaecol India 2002;52(1):164.

2. Bucello D, Frederic B, Noel JC. Giant cervical polyp: a case report and review of rare entity. Arch Gynecol Obstet 2008; 278(3):295-298

3. Massinde AN, Mpogoro F, Rumanyika RN, Magona M. Uterine prolapsed complicated with giant cervical polyp. J Low Genit Tract Dis 2012;16(1):64-65.

4. Surana AD, et al. Huge Fibroid: Polyp - a case report. Sch J Med Case Rep 2014;2(2):78-79.

5. Abedi O. Harrison. Prolapsed giant cervical fibroid polyp mimicking procidentia - aftermath of traditional therapy for fibroids-a case report and review of the literature. Open Sci J Clin Med 2014;2(1):15-18.

6. Lippert LJ, Richart RM, Ferenczy A. Giant benign endocervical polyp: report of a case. Am J Obstet Gynecol 1974;118(8): 1140-1141.

7. Gögüs S, Senocak ME, Arda IS, et al. Multilocular endocervical polyp in a 5 years old girl. Pediatr Pathol 1993;13:415-419.

8. Khalil AM, Azar GB, Kasper HG, Abu-Musa AA, Chararah IR, Seoud MA. Giant cervical polyp: a case report. J Reprod Med 1996 Aug;41(8):619-621. 